\title{
INTERCALATION OF POLYETHYLENE OXIDE IN LAYERED THIOPHOSPHATE OF BI AND SB
}

\author{
DOMINGO RUIZ LEÓN, ANTONIO GALDÁMEZ AND VÍCTOR MANRÍQUEZ
}

\author{
Universidad de Chile, Facultad de Ciencias, \\ Departamento de Química, Casilla 653, Santiago, Chile \\ (Received: 26 November 2007 - Accepted: 6 March 2008)
}

\begin{abstract}
The intercalation compounds $\mathrm{Li}_{0.43}(\mathrm{PEO})_{2.4}\left(\mathrm{H}_{2} \mathrm{O}\right)_{1.4} \mathrm{~K}_{0.57} \mathrm{BiP}_{2} \mathrm{~S}_{6}$ and $\mathrm{Li}_{0.38}(\mathrm{PEO})_{2.1}\left(\mathrm{H}_{2} \mathrm{O}\right)_{1.6} \mathrm{~K}_{0.62} \mathrm{SbP}_{2} \mathrm{~S}_{6}$ have been synthesized by the insertion of polyethylene oxide $\mathrm{PEO}$ in $\mathrm{LiKMP}_{2} \mathrm{~S}_{6}(\mathrm{M}=\mathrm{Bi}, \mathrm{Sb})$, that contained $\mathrm{Li}^{+}$and $\mathrm{K}^{+}$exchangeable cations in their interlayer space. The polymer PEO is able to associate interlayer $\mathrm{Li}^{+}$ cation modifying the ionic conductivity of pristine phases. These intercalation compounds constitute a new family of intercalates in the thiophosphate of Bi and $\mathrm{Sb}$ with Polyethylene oxide as guest species. They have been characterized by powder X-ray diffraction, FTIR-Raman, DTA/TGA analysis and electrical conductivity measurements. The studied nanocomposite shows values of electrical conductivity $\left(\sigma_{\mathrm{i}}\right)$ of about $10^{-6} \Omega^{-1} \mathrm{~cm}^{-1}$ at room temperature.
\end{abstract}

Keyword: Intercalation, Chalcogenides, Layered compound

\section{INTRODUCTION}

The quaternary chalcophosphate compounds $\mathrm{AM}_{\mathrm{X}} \mathrm{P}_{\mathrm{y}} \mathrm{Q}_{\mathrm{x}}$ containing Bi and $\mathrm{Sb}$, have attracted the attention of many workers because of their interesting anisotropic physical properties as well as potential technological applications 1,2 . The chalcophosphates of the type $\mathrm{AMP}_{2} \mathrm{Q}_{6}(\mathrm{~A}=$ alkaline metals, $\mathrm{M}=\mathrm{Sb}, \mathrm{Bi}$ and $\mathrm{Q}=\mathrm{S}, \mathrm{Se})$ are materials that present the anions $\left(\mathrm{P}_{2} \mathrm{Q}_{6}\right)^{4}$ that are coordinated to the metals $\mathrm{A}$ and $\mathrm{M}$ through the chalcogen atoms $\mathrm{Q}{ }^{1,3-4}$. An important characteristic of the $\mathrm{Bi}$ and $\mathrm{Sb}$ atoms, in solid phases, is the stereochemical localization of the $\mathrm{ns}^{2}$ electron pairs, which produces important variations in crystal structure, physical properties and electronic structure of the resulting materials. Thus, these materials possess different crystalline structures, presenting one-dimensional $1 \mathrm{D}$, two-dimensional $2 \mathrm{D}$ and three-dimensional 3D structures. The phases $\mathrm{M}_{4}\left(\mathrm{P}_{2} \mathrm{Se}_{6}\right)_{3}(\mathrm{M}=\mathrm{Bi}, \mathrm{Sb})$ exhibit structures related to $\mathrm{Pb}_{2} \mathrm{P}_{2} \mathrm{Se}_{6}{ }^{5}$, while the phase $\beta-\mathrm{Bi}_{4}\left(\mathrm{P}_{2} \mathrm{Se}_{{ }^{2}}\right)_{3}$ exhibits a three-dimensional (3D) structure ${ }^{6}$, with groups $\mathrm{BiSe}_{8}$ and $\mathrm{P}_{2} \mathrm{Se}^{4}{ }^{4}$. The quaternary chalcophosphates $\mathrm{KMP}_{2} \mathrm{Q}_{6}(\mathrm{M}=\mathrm{Bi}, \mathrm{Sb}$ and $\mathrm{Q}=\mathrm{S}, \mathrm{Se})$ exhibit two-dimensional (2D) structures, where the potassium atoms are located in the interlayer ${ }^{7-9}$. Measures of electric conductivity, carried out in $\mathrm{Cs}_{8} \mathrm{M}_{4}\left(\mathrm{P}_{2} \mathrm{Se}_{6}\right)_{5}$, indicate behaviors of semiconductors material with values of electrical conductivity, $\sigma_{\mathrm{t}}, 10^{-9} \mathrm{~S} / \mathrm{cm}$ at room temperature ${ }^{10}$.

The revival of interest in layered materials is originates from the observation of unusual physical properties and anisotropy phenomena. Since the physical properties of these materials can be modified significantly by intercalation, this aspect in turn resulted in a renewed strong motivation in the area of synthetic chemistry, for the search after novel host-lattices and intercalation compounds 11 .

An other hand, the intercalation of large molecule into layered compounds is a topic of great interest, due that the intercalates can have in some cases physical properties very different from those of the pure host lattice ${ }^{12-13}$. The intercalation of organic polymers in layered inorganic host materials to form organic/inorganic nanostructures has focused increasing interest because such systems can show physical and chemical behaviour synergistically derived from both host and guest ${ }^{12-13}$. The polyethylene oxide (PEO) is one of such polymer that has been successfully intercalated into layered structures such as montmorillonite ${ }^{14}, \mathrm{~V}_{2} \mathrm{O}_{5}{ }^{15}, \mathrm{MS}_{2}(\mathrm{M}=\mathrm{Mo}, \mathrm{Ti}){ }^{16}, \mathrm{MoO}_{3}{ }^{17}, \mathrm{MPS}_{3}(\mathrm{M}=\mathrm{Mn}$, $\mathrm{Cd}, \mathrm{Ni}, \mathrm{Fe})^{18}$.

In order to obtain new organic/inorganic composite with novel host lattice. We described here the ability of polyethylene oxide to be intercalated into the van der Waals gap of the lamellar $\operatorname{LiKMP}_{2} \mathrm{~S}_{6}(\mathrm{M}=\mathrm{Sb}, \mathrm{Bi})$ in a topotactic process giving rise to air-stable intercalates.

\section{EXPERIMENTAL}

\section{Preparation of Host compounds}

The phases $\mathrm{KMP}_{2} \mathrm{~S}_{6}(\mathrm{M}=\mathrm{Bi}, \mathrm{Sb})$ were synthesized by direct combination of the pure elements in stoichiometric proportions, with an excess of chalcogen and phosphorus $(1 \%$ mass) to avoid the formation of impurity phases. The reaction mixtures were sealed in evacuated quartz ampoules, and heated at $1023 \mathrm{~K}$ for one week. After the reaction was completed, the reacted matter was slowly cooled to room temperature at the rate of $6 \mathrm{~K} / \mathrm{h}$. Homogeneous and well-crystallized materials were obtained after grinding and reheating at 1023 $\mathrm{K}$ for one week. The reaction product was washed with DMF/ethylenediamine (3:1) to remove the $\mathrm{P}_{y} \mathrm{Q}_{z}$ and $\mathrm{Q}$. SEM-EDX analyses carried out on the samples confirmed their purity, homogeneity and stoichiometry.

\section{Preparation of Intercalation compounds}

The intercalation of $\mathrm{Li}$ was success fully carry out by reaction of pure $\mathrm{KMP}_{2} \mathrm{~S}_{6}(\mathrm{M}=\mathrm{Bi}, \mathrm{Sb})$ and $\mathrm{Li}_{2} \mathrm{~S}$ in stoichiometric amounts, sealed in evacuated quartz tubes, and then heated at $723 \mathrm{~K}$ for 1 weeks. After the reaction was completed, the reacted matter was slowly cooled to room temperature. The intercalation of PEO was achieved by treatment of aqueous suspension of the intermediate compounds LiKMP $\mathrm{S}_{6}$ phase with an acetonitrile solution of PEO under vigorous shacking ( $24 \mathrm{~h}$. at room temperature). Finally, the resulting product was washed with acetonitrile and vacuum dried.

\section{Characterization}

Both the host- and intercalation compounds were characterized by EDX, XRD and FTIR-Raman. The elemental analyses were obtained by EDX and for all compounds described here. SEM-EDX analyses were obtained on a CAMECA SU 30 with detector PRINCETON GAMMA. The X-ray powder diffraction (XRD) data were collected at room temperature on a Siemens D 5000 powder diffractometer, with $\mathrm{CuK}_{\alpha}$ radiation in the range $5<2 \theta<60^{\circ}$.

The infrared spectra were obtained in the range $4000-370 \mathrm{~cm}^{-1}$ on samples pressed into $\mathrm{KBr}$ disk using a Perkin Elmer FTIR-Raman spectrometer system 2000. All Raman spectra presented were recorded in Renishaw system 2000 in the range $3000-100 \mathrm{~cm}^{-1}$, using laser excitation at $633 \mathrm{~nm} \mathrm{He}-\mathrm{Ne}$ and laser power of $2.5 \mathrm{~mW}$ at the sample. All measurements were made in a back-scattering geometry, using a $50 \mathrm{x}$ microscope objective with a numerical aperture value of 0.75 , providing scattering areas (spatial resolution) of $1 \mu \mathrm{m}^{2}$. Single point spectra were recorded with $4 \mathrm{~cm}^{-1}$ resolution and $10 \mathrm{~s}$ accumulation times.

The Differential Thermal analysis (DTA) and Thermal Gravimetric analysis (TGA) were performed on a STA $1500 \mathrm{H} / 625$ Thermal analysis system, Rhoeometric scientific. The DTA - TG curves were run simultaneously on each sample from room temperature at $1273 \mathrm{~K}$, in flowing atmosphere of nitrogen using a heating rate of $10 \mathrm{~K} / \mathrm{min}$.

Electrical conductivity of the samples was measured by an ac and dc method on cylindrical disk samples, mounted between two gold electrodes. The ac conductivity measurements were carried out by an ac complex impedance analysis in the frequency range from $0.1 \mathrm{~Hz}$ to $10 \mathrm{MHz}$ by Solartron SI 1260 Impedance /Gain Phase Analyser with a signal level 0.2 to $1 \mathrm{~V}$. Direct current (dc) conductivity was determined by an Keithley 237 source-meter. The Ohmicity was checked, there was no evidence of any nonlinearity in the I-V characteristics. All the measurements were found to be reproducible.

\section{RESULTS AND DISCUSSION}

It is know that cations could be intercalated into layered phases such as $\operatorname{AMPS}_{3}(\mathrm{~A}=\mathrm{Na}, \mathrm{K}$ and $\mathrm{M}=\mathrm{Mn}, \mathrm{Fe}, \mathrm{Ni}, \mathrm{Cd})$ following an ion-exchange process in which the alkaline ions are replaced ${ }^{19-20}$. However all attempts to intercalation 
of $\mathrm{Li}^{+}$into $\mathrm{KMP}_{2} \mathrm{~S}_{6}(\mathrm{M}=\mathrm{Bi}, \mathrm{Sb})$ host matrix by ion-exchange reaction from salt aqueous solutions failed. The partial intercalation of $\mathrm{Li}^{+}$was success carried following the procedure by the low temperature topotactic solid-solid ionexchange reported by M.G. Kanatzidis et al. ${ }^{21}$, where the $\mathrm{K}+$ ions are replaced by the smaller cations $\mathrm{Li}+$ according with:

$$
\mathrm{KMP}_{2} \mathrm{~S}_{6}+\mathrm{Li}_{2} \mathrm{~S} \rightarrow \mathrm{LiMP}_{2} \mathrm{~S}_{6}+\mathrm{K}_{2} \mathrm{~S}
$$

The treatment of the $\mathrm{KMP}_{2} \mathrm{~S}_{6}$ compounds with $\mathrm{Li}_{2} \mathrm{~S}$ results in a partial $\mathrm{K}^{+}-\mathrm{Li}^{+}$exchange, this leads to the desire intercalated materials with a small cations. We noted that the interplanar spacing calculated from XRD patterns is very close to the values for the pure starting $\mathrm{KMP}_{2} \mathrm{~S}_{6}$ host matrix, we have previously reported the crystal structure of the phases $\mathrm{KMP}_{2} \mathrm{~S}_{6}(\mathrm{M}=\mathrm{Bi}, \mathrm{Sb})$, which are shows in figure $1^{8-9}$. The values of the basal spacing, such as the ir spectra, are consistent with the size of the cationic guest species $\mathrm{Li}^{+}$. In addition the presence of lithium is noticed in the Raman spectra essentially by a new weak band which is located at $323 \mathrm{~cm}^{-1}$ (Fig. 2). This new peak is interpreted as a stretching mode due to vibration of Lithium atoms located in the van der Waals gap against the nearest neighbouring sulphur atoms like $\mathrm{LiS}_{6}$ entities ${ }^{22}$ Finally, according to elemental analysis, the intercalation compounds prepared may be formulated as $\mathrm{Li}_{0.43} \mathrm{~K}_{0.57} \mathrm{BiP}_{2} \mathrm{~S}_{6}$ and $\mathrm{Li}_{0.38} \mathrm{~K}_{0.62} \mathrm{SbP}_{2} \mathrm{~S}_{6}$.

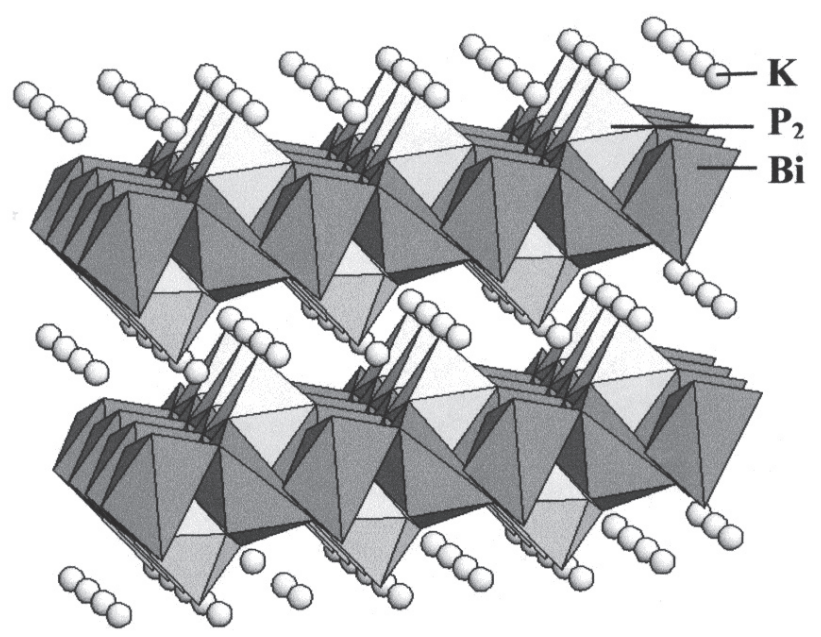

Fig. 1. Crystal structure of $\mathrm{KBiP}_{2} \mathrm{~S}_{6}$ viewed along a-axis

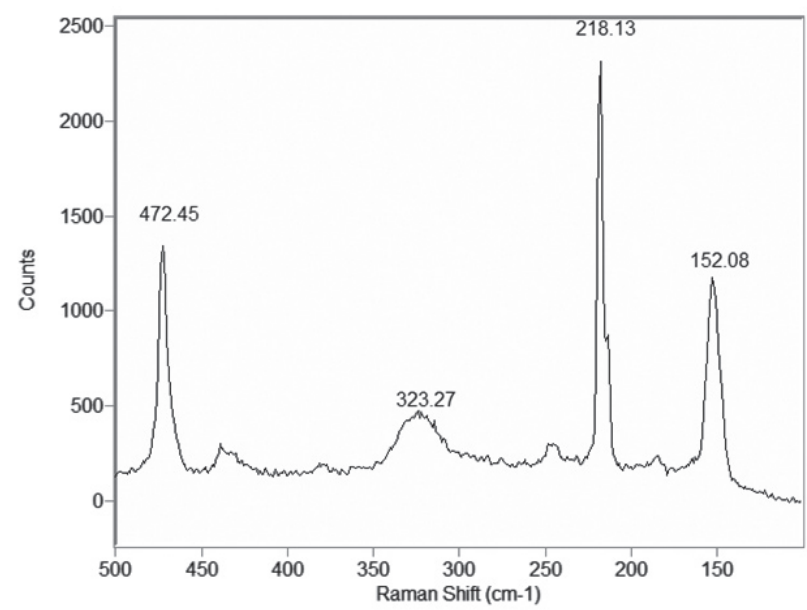

Fig. 2. Raman Spectra for $\mathrm{Li}_{0.38} \mathrm{~K}_{0.62} \mathrm{SbP}_{2} \mathrm{~S}_{6}$

The kinetics of intercalation of organic polymers into layered compounds is generally unfavourable due to the high activation energy associated with the deformation of the crystal structure of the inorganic host species. Thus, the insertion process requires the expansion of the interlayer spacing by a previous intercalation of simple small hydrated ions ${ }^{23}$. The $\mathrm{Li}(\mathrm{PEO}) \mathrm{KMP}_{2} \mathrm{~S}_{6}$ nanocomposite was obtained by reaction of the intermediate $\operatorname{LiKMP}_{2} \mathrm{~S}_{6}$ with PEO. To swell the layers apart, we form, in a first step, an aqueous suspension of LiKMP $\mathrm{S}_{6}$. The stoichiometry of the final products $\mathrm{Li}_{0.43}(\mathrm{PEO})_{2.4}\left(\mathrm{H}_{2} \mathrm{O}\right)_{1.4} \mathrm{~K}$ ${ }_{0.57} \mathrm{BiP}_{2} \mathrm{~S}_{6}$ and $\mathrm{Li}_{038}(\mathrm{PEO})_{21}\left(\mathrm{H}_{2} \mathrm{O}\right)_{1.6} \mathrm{~K}_{0.62} \mathrm{SbP}_{2} \mathrm{~S}_{6}$ were determined by elemental analysis and thermal gravimetric measurement. The Tables 1 and 2 summarizes the analytical data for the obtained intercalation compounds, slight deviations from the ideal composition may reflect some heterogeneity of the samples. The studied nanocomposite show a mass losses of $8.3 \%$ below $200^{\circ} \mathrm{C}$ and $41.6 \%$ at $320^{\circ} \mathrm{C}$, which are ascribed to dehydration and PEO decomposition, respectively. The material is thermally stable under nitrogen up to $260^{\circ} \mathrm{C}$.

Table 1. Analytical and XRD data for $\mathrm{Li}_{0.43}(\mathrm{PEO})_{2.4}\left(\mathrm{H}_{2} \mathrm{O}\right)_{1.4} \mathrm{~K}_{0.57} \mathrm{BiP}_{2} \mathrm{~S}_{6}$ nanocomposite

\begin{tabular}{|c|c|c|c|c|c|c|c|}
\hline Basal spacing & $\mathbf{H}_{\mathbf{2}} \mathbf{O}$ & $\left(\mathbf{C}_{\mathbf{2}} \mathbf{H}_{\mathbf{4}} \mathbf{O}\right)_{\mathbf{n}}$ & \multicolumn{5}{|c|}{ Analytical data (\%w/w) } \\
\hline $\mathrm{d} / \AA$ & $\Delta \mathrm{m} \%$ & $\Delta \mathrm{m} \%$ & $\mathrm{Li}$ & $\mathrm{K}$ & $\mathrm{P}$ & $\mathrm{S}$ & $\mathrm{Bi}$ \\
\hline 14.5 & 4.10 & 17.10 & 0.48 & 3.60 & 10.00 & 31.10 & 33.70 \\
\hline
\end{tabular}

Table 2. Analytical and XRD data for $\mathrm{Li}_{0.38}(\mathrm{PEO})_{2.1}\left(\mathrm{H}_{2} \mathrm{O}\right)_{1.6} \mathrm{~K}_{0.62} \mathrm{SbP}_{2} \mathrm{~S}_{6}$ nanocomposite

\begin{tabular}{|c|c|c|c|c|c|c|c|}
\hline $\begin{array}{c}\text { Basal } \\
\text { spacing }\end{array}$ & $\mathbf{H}_{2} \mathbf{O}$ & $\left(\mathbf{C}_{2} \mathbf{H}_{4} \mathbf{O}\right)_{\mathbf{n}}$ & \multicolumn{5}{|c|}{ Analytical data (\%w/w) } \\
\hline $\mathrm{d} / \AA$ & $\Delta \mathrm{m} \%$ & $\Delta \mathrm{m} \%$ & $\mathrm{Li}$ & $\mathrm{K}$ & $\mathrm{P}$ & $\mathrm{S}$ & $\mathrm{Sb}$ \\
\hline 14.3 & 5.50 & 17.60 & 0.50 & 4.62 & 11.82 & 36.70 & 23.23 \\
\hline
\end{tabular}

The PEO intercalated composites were characterized by X-ray powder diffraction (XRD). The XRD patterns of the intercalate shows a significant loss of crystallinity, compare with pristine $\mathrm{KMP}_{2} \mathrm{~S}_{6}$ with sharp $00 l$ reflection which yield an interlamellar distance of $14.5 \AA$. The Fig. 3 shows the XRD pattern of $\mathrm{Li}_{0.43}(\mathrm{PEO})_{2.4}\left(\mathrm{H}_{2} \mathrm{O}\right)_{1.4} \mathrm{~K}_{0.57} \mathrm{BiP}_{2} \mathrm{~S}_{6}$ compared with pristine $\mathrm{Li}_{0.43} \mathrm{~K}_{0.57} \mathrm{BiP}_{2} \mathrm{~S}_{6}$. The basal spacing increases found can be interpreted as the intercalation of PEO with helical conformation, or as a two-layer arrangement of PEO chains in a zigzag conformation.

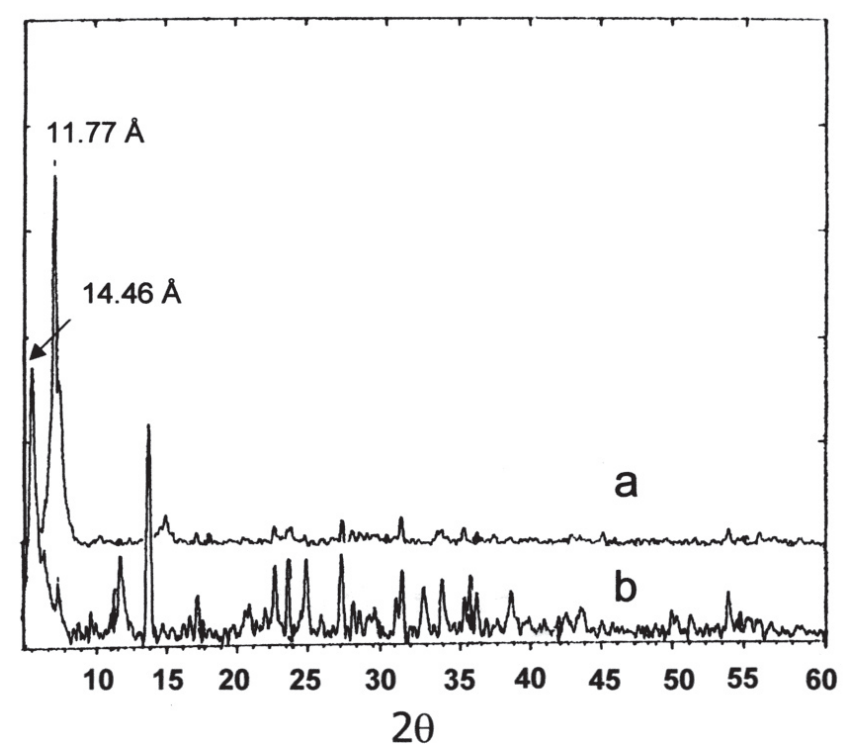

Fig. 3. Powder $\mathrm{X}$-ray diffractions patterns of a) $\mathrm{Li}_{0.43} \mathrm{~K}_{0.57} \mathrm{BiP}_{2} \mathrm{~S}_{6}$ b) $\mathrm{Li}_{0.43}(\mathrm{PEO})_{2.4}\left(\mathrm{H}_{2} \mathrm{O}\right)_{1.4} \mathrm{~K}_{0.57} \mathrm{BiP}_{2} \mathrm{~S}_{6}$

The IR spectra of the intercalates (Fig. 4) shows some characteristic bands attributed to $\mathrm{CH}_{2} \mathrm{CH}_{2} \mathrm{O}$ groups (Table 3 ) and display two strong bands at 598 and $495 \mathrm{~cm}^{-1}$ arising from the splitting of the $v\left(\mathrm{PS}_{3}\right)$ stretching band occurs at $570 \mathrm{~cm}^{-1}$ in pristine KMP $\mathrm{S}_{6}$. The splitting reflects the presence of intralamellar guest species ${ }^{24}$. The broad Strong band centered a $2890 \mathrm{~cm}^{-1}$ in bulk PEO, 
associated with $\mathrm{CH}_{2}$ stretching modes appears in the intercalate form like two weak bands at 2855 and $2929 \mathrm{~cm}^{-1}$. This behaviour is commonly found in other PEO nanocomposites and has been ascribed to interactions between oxygen atoms in PEO and interlayer cation ${ }^{25}$. Both XRD and IR data confirm the intercalation of PEO in $\mathrm{LiKMP}_{2} \mathrm{~S}_{6}(\mathrm{M}=\mathrm{Bi}, \mathrm{Sb})$ host matrix.

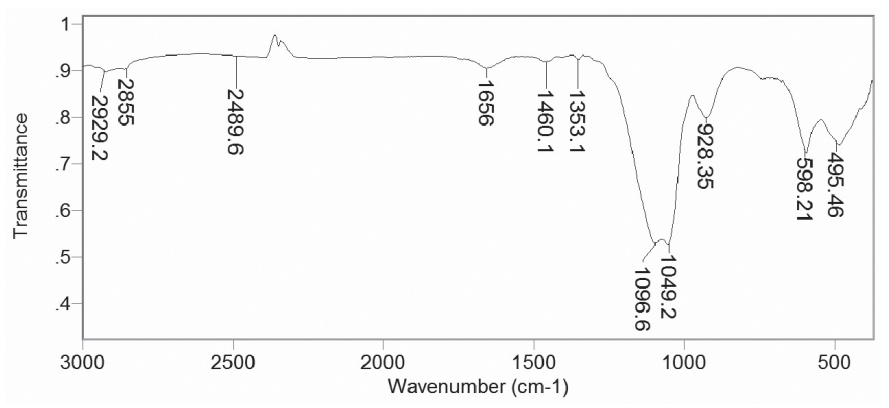

Fig. 4. FT-IR spectra for $\mathrm{Li}_{0.43}(\mathrm{PEO})_{2.4}\left(\mathrm{H}_{2} \mathrm{O}\right)_{1.4} \mathrm{~K}_{0.57} \mathrm{BiP}_{2} \mathrm{~S}_{6}$

Table 3. IR spectra assignments of the intercalated phase

\begin{tabular}{|c|c|}
\hline Frequency $\left(\mathrm{cm}^{-1}\right)$ & Assignment \\
\hline 2929,2855 & $\delta\left(\mathrm{CH}_{2}\right)$ \\
\hline 1460,1353 & $\left(\mathrm{CH}_{2}\right)$ \\
\hline 1100 & $\delta(\mathrm{CO})$ \\
\hline 598,495 & $v\left(\mathrm{PS}_{3}\right)$ \\
\hline 928 & $v(\mathrm{C}-\mathrm{C})$ \\
\hline
\end{tabular}

The experimental stoichiometry is around two $\mathrm{CH}_{2} \mathrm{CH}_{2} \mathrm{O}$ units per LiKMP $\mathrm{S}_{6}$ formula, suggesting that the arrangement is less dense than a double layer of linear zigzag like PEO chains. Thus, the PEO chains solvating the $\mathrm{Li}^{+}$ ion may exhibit a helical structure similar to that found in the corresponding PEO intercalates into MPS $(\mathrm{M}=\mathrm{Mn}, \mathrm{Cd})^{18}$ and for the PEO-Lithium salt solid electrolytes ${ }^{26}$. It is reasonable to assume that solvation of the $\mathrm{Li}^{+}$ion by the oxygen atoms of the polyethylene oxide is the driving force of the polymer insertion process.

The electrical conductivity was measured at room temperature, with samples under dry $\mathrm{N}_{2}$ flow. A.c. impedance data were obtained in the $10^{5}$ $10^{-2} \mathrm{~Hz}$ range. Typical complex impedance plane plots show an arc (Nyquist diagram) displaced from the origin (Fig. 5). The total resistance is deduced from the intercept of the arc with the real axis at the lowest frequency values. Direct current (dc) measurements were performed, to ascertain the existence of slow relaxation mechanisms that may not be accessible through the impedance measurements.

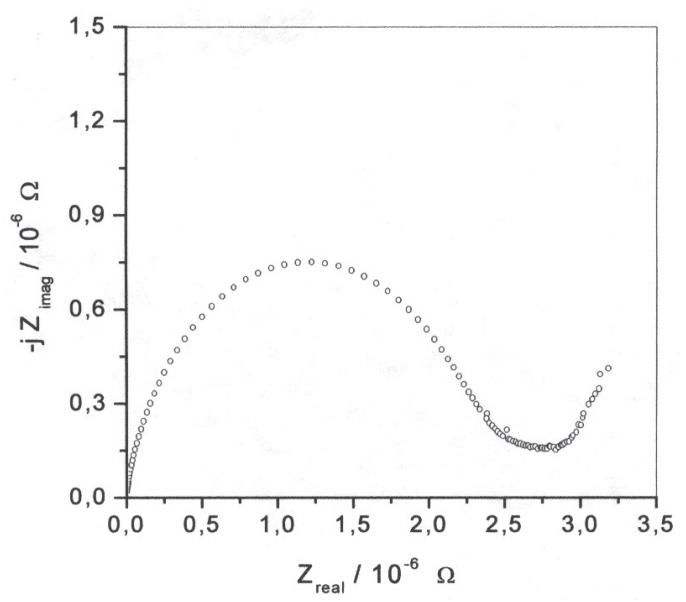

Fig. 5. Impedance plot and Nyquist diagram for $\mathrm{Li}_{043}(\mathrm{PEO})_{24}\left(\mathrm{H}_{2} \mathrm{O}\right)_{14}$ $\mathrm{K}_{0.57} \mathrm{BiP}_{2} \mathrm{~S}_{6}$
The electrical conductivity at room temperature of $\mathrm{KMP}_{2} \mathrm{~S}_{6}$ is ca. $10^{-7}$ $\mathrm{S} / \mathrm{cm}$. The intercalation of PEO also produce an enhance of the conductivity associated with ionic-conductivity to values, at room temperature, $10^{-6} \mathrm{~S} / \mathrm{cm}$ (dc measurements). In addition it can be seen that the electrical conductivity is sensitive to other ionic species, as $\mathrm{H}_{3} \mathrm{O}^{+}$, present in the system (Table 4).

Table 4. Conductivity values $(\sigma)$ at $298 \mathrm{~K}$ from dc method

\begin{tabular}{|c|c|}
\hline Compounds & $\boldsymbol{\sigma}\left(\boldsymbol{\Omega}^{-1} \mathbf{c m}^{-1}\right)$ \\
\hline $\mathrm{KBiP}_{2} \mathrm{~S}_{6}$ & $1,8 \times 10^{-7}$ \\
\hline $\mathrm{KSbP}_{2} \mathrm{~S}_{6}$ & $3,6 \times 10^{-7}$ \\
\hline $\mathrm{Li}_{0.43}(\mathrm{PEO})_{2.4}\left(\mathrm{H}_{2} \mathrm{O}\right)_{1.4} \mathrm{~K}_{0.57} \mathrm{BiP}_{2} \mathrm{~S}_{6}$ & $1.9 \times 10^{-6}$ \\
\hline $\mathrm{Li}_{0.38}(\mathrm{PEO})_{2.1}\left(\mathrm{H}_{2} \mathrm{O}\right)_{1.6} \mathrm{~K}_{0.62} \mathrm{SbP}_{2} \mathrm{~S}_{6}$ & $4.3 \times 10^{-6}$ \\
\hline
\end{tabular}

\section{ACKNOWLEDGMENTS}

The authors wish to dedicate this work to the memory of Dr. Jaime Retuert, a fine Professor and a very good friend. This work was supported by FONDECYT grant $\mathrm{N}^{\circ} 1061116$

\section{REFERENCES}

1. M.G. Kanatzidis, Curr. Opinion Solid State Mater. Sci. 2, 139, (1997).

2. a) M. A. Gave, D. Bilc, S.D. Mahanti, J. D. Breshears an M. Kanatzidis, Inorg. Chem. 44, 5293, (2005) .

b) A. Galdámez, V. Manríquez, J. Kasaneva and R. E. Ávila, Mater. Res. Bull. 38, 1063, (2003).

3. T. McCarthy, M. Kanatzidis, J. Alloys Compd. 236, 70, (1996).

4. J. Breshears and M. Kanatzidis, J. Am. Chem.Soc. 122, 7839, (2000).

5. M. Ruck, Z. Anorg. Allg. Chem. 621, 1344, (1995).

6. J. Aitken, S. Brown, K Chondroudis, S. Jobic, R. Brec and M. Kanatzidis, Inorg. Chem. 38, 4795, (1999).

7. T. McCarthy and M. Kanatzidis, Chem Commun. 1089, (1994).

8. V. Manríquez, A. Galdámez, D. Ruiz-León and M.T. Garland, Z. Krist.New Cryst. St. 218, 151, (2003).

9. V. Manríquez, A. Galdámez, D. Ruiz-León, and M.T. Garland, Z. Krist. New Cryst. St. 218, 403, (2003).

10. T. McCarthy, T. Hogan, C. Kannnewurf and M. Kanatzidis, Chem. Mater. 6, 1072, (1994).

11. R. Clèment, L. Lomas and J.P. Audière, Chem. Mater. 2, 641, (1990).

12. L. Lomas, P. Lacroix, J.P. Audière and R. Clèment, J. Mater.Chem. 1, 475, (1991).

13. E. Ruiz-Hitzky, Adv. Mater. 5, 334, (1993).

14. P. Aranda, E. Ruiz-Hitzky, Chem. Mater. 4, 1395, (1992).

15. E. Ruiz-Hitzky, P. Aranda, B. Casal, J. Mater. Chem. 2, 581, (1992).

16. E. Ruiz-Hitzky, R. Jimenez, B. Casal, V. Manríquez, A. Santa Ana, G. González, Adv. Mater. 5, 738, (1993).

17. L.F. Nazar, H. Wu, W.P. Power, J. Mater. Chem. 5, 1985, (1995).

18. a) I. Lagadic, A. Le'austic, R. Clément, Chem. Commun. 1396, (1992). b) V. Manríquez, P. Barahona, D. Ruiz and R. Avila, Mater. Res. Bull., 40, 475, (2005).

19. R. Clément, J.Am.Chem.Soc. 103, 6998, (1981).

20. R. Clément, A. Leaustic, K. Marney and A.H. Francis, J. Phys.Chem. Solids 55, 9, (1994).

21. K. Chondroudis and M.G. Kanatzidis, J. Solid State Chem. 136, 328 , (1998).

22. I. Kerrache, c. Julien, C. Sourisseau, Solid State Ionics 92, 37, (1996).

23. R. Clément, O. Garnier and J. Jegoudez, Inorg. Chem. 25, 1404, (1986).

24. Y. Mathey, R. Clément, C. Sourisseau and G. Lucazeau, Inorg.Chem. 19, 2773, (1980).

25. H. Lourdes, J. Morales and J. Santos, J. Solid State Chem. 141, 323, (1998).

26. M. A. Ratner and D.F. Shriver, Chem.Rev. 88, 109, (1988). 